\title{
Comparison of CTG repeat length expansion and clinical progression of myotonic dystrophy over a five year period
}

Unitat de Genetica Molecular, Hospital de Sant Pau, Avda S Antoni Ma Claret 167, 08025 Barcelona, Spain

L Martorell

M Baiget

Servei de Neurologia, Consorci Hospitalari Parc Tauli, Sabadell, Spain

J M Martinez

Genetics Unit,

Department of

Anatomy, Charing

Cross and

Westminster Medical

School, Fulham

Palace Road, London

W6 8RF, UK

N Carey

K Johnson

Correspondence to: Dr Baiget.

Received 23 December 1994 Revised version accepted for Revised version accepted for
publication 15 March 1995

\author{
L Martorell, J M Martinez, N Carey, K Johnson, M Baiget
}

\begin{abstract}
Myotonic dystrophy (DM) is associated with an underlying CTG trinucleotide repeat expansion at a locus on chromosome 19q13.3. We have determined the repeat length in 23 DM patients with varying clinical severity of symptoms and various sizes of repeat amplification. We confirm that as in previous studies there is no strong correlation between repeat length and clinical symptoms but find that the repeat length in peripheral blood cells of patients increases over a time span of five years indicating continuing mitotic instability of the repeat throughout life. Repeat length progression does not appear to be indicative of clinical progression but age probably is. The degree of expansion correlates with the initial repeat size and $50 \%$ of the patients with continuing expansions showed clinical progression of their disease symptoms over the five year study period.
\end{abstract}

( $\mathcal{F}$ Med Genet 1995;32:593-596)

Myotonic dystrophy (DM) is a multisystemic disorder characterised by a highly variable clinical phenotype including myotonia, progressive muscle weakness, and cataract. It is inherited as an autosomal dominant trait and is the commonest cause of adult muscular dystrophy. ${ }^{1}$ All DM mutations characterised to date exhibit amplifications of a CTG trinucleotide repeat located in the $3^{\prime}$ untranslated region of a protein kinase gene (DMPK) on chromosome $19 \mathrm{q} 13.3 .{ }^{2-7}$ A positive correlation is seen between earlier onset/greater severity and increasing CTG repeat number. ${ }^{8}$ The number of CTG repeats at this locus within the general population has been shown to be highly polymorphic. ${ }^{9}$ Intergenerational expansion of the repeat length is seen in DM families and underlies the phenomenon of anticipation. ${ }^{10}$

Little is known of the pathological processes which lead from a CTG expansion to the disease phenotype, or about the mechanisms which determine repeat size and stability. Southern analysis of DM genomic DNA samples identifies smears of heterogeneous length fragments in the DM allele and tissue variability of the repeat size in individual DM patients. ${ }^{11}$ The different expansion patterns seen in monozygous DM twins also seem to indicate a high degree of mitotic instability. ${ }^{12}$ Previous investigations of the instability of the repeats with time have shown a difference in the peripheral blood lymphocytes of patients compared to their transformed lymphoblastoid cell lines after many passages. ${ }^{13}$

In this paper we present data obtained from 23 DM patients with differing severities of phenotype and various sizes of CTG expansion. We have determined the length of the repeat in DNA of peripheral blood lymphocytes taken at intervals of five years between visits. We show that the repeat length in DM patients' blood cells is continuing to expand with time, indicating continuing mitotic instability in this condition. We show that the degree of expansion seen in this timeframe correlates with the initial size of the repeat.

\section{Materials and methods}

Twenty three DM patients whose DNA samples were analysed for molelcular diagnosis or presymptomatic testing five years ago were recontacted and a new blood sample obtained. The patients were grouped into four different classes based on age of onset and severity of symptoms: A (asymptomatic obligate carriers), B (late onset with minimal features of the disease), C (classic adult onset), and D (early onset cases and congenitally affected). The patients were re-evaluated when they came for their repeat blood sample by the neurologist who saw them originally using the same diagnostic criteria. The clinical parameters examined included the following.

Muscle involvement:

Myotonia shown by either clinical or percussion myotonia or myotonia of the hand muscles tested following a foreceful grip.

Atrophy of the distal muscles of the forearm or dorsiflexors of the foot.

Weakness resulting from involvement of facial, neck, and distal limb muscles, graded by MRC scale.

Ocular abnormalities:

Minor alterations, including cortical spokes or star shaped opacities seen with the ophthalmoscope.

Unilateral cataracts, as detected by slit lamp examination showing numerous opacities in one lens or a mature cataract in one eye.

Bilateral cataract associated with marked diminution of visual acuity.

Cardiac manifestations:

ECG abnormalities, including slight conduction defects such as prolonged PR interval or QRS.

Right or left bundle branch block found on 


\begin{tabular}{|c|c|c|c|c|c|}
\hline \multirow{2}{*}{$\begin{array}{l}\text { Patient } \\
\text { No }\end{array}$} & \multirow{2}{*}{$\begin{array}{l}\text { Age at } \\
\text { diagnosis }\end{array}$} & \multirow{2}{*}{$\begin{array}{l}\text { Clinical } \\
\text { severity* }\end{array}$} & \multirow{2}{*}{$\begin{array}{l}\text { Clinical } \\
\text { progressiont }\end{array}$} & \multicolumn{2}{|c|}{$(C T G) n(k b) \neq$} \\
\hline & & & & 1989 & 1994 \\
\hline 1 & 44 & A & No & $\begin{array}{l}10 \cdot 2 \\
(100\end{array}$ & $\begin{array}{l}10 \cdot 2 \\
100)\end{array}$ \\
\hline 2 & 46 & A & No & $\begin{array}{l}10 \cdot 1 \\
(65\end{array}$ & $\begin{array}{l}10 \cdot 1 \\
65)\end{array}$ \\
\hline $3 \S$ & 18 & A & No & $\begin{array}{l}10.5 \\
(138 \\
10.2 \\
(115\end{array}$ & $\begin{array}{l}10 \cdot 5 \\
138) \\
10 \cdot 2 \\
115)\end{array}$ \\
\hline $4 \S$ & 20 & A & No & $\begin{array}{l}10.5 \\
(138 \\
10.2 \\
(85\end{array}$ & $\begin{array}{l}10 \cdot 5 \\
138) \\
10 \cdot 2 \\
85)\end{array}$ \\
\hline 5 & 29 & A & $\begin{array}{l}\text { Jaw myotonia } \\
\text { Weakness of neck flexors } 5 \rightarrow 4\end{array}$ & $10 \cdot 5$ & $10 \cdot 5$ \\
\hline 6 & & A & ND & $\begin{array}{l}10 \cdot 2 \\
(120\end{array}$ & $\begin{array}{l}10 \cdot 2 \\
120)\end{array}$ \\
\hline 7 & 25 & B & $\begin{array}{l}\text { Bilateral cataracts } \\
\text { Weakness of foot dorsiflexors } 5 \rightarrow 4 \\
\text { Weakness of neck flexors } 5 \rightarrow 4\end{array}$ & $10 \cdot 8$ & $11 \cdot 2$ \\
\hline 8 & 18 & $\begin{array}{l}\text { B } \\
\text { B }\end{array}$ & $\begin{array}{l}\text { No } \\
\text { ND }\end{array}$ & $\begin{array}{l}11 \cdot 0 \\
10 \cdot 2\end{array}$ & $\begin{array}{l}11 \cdot 0 \\
10.5\end{array}$ \\
\hline $\begin{array}{l}10 \\
11\end{array}$ & $\begin{array}{l}22 \\
19\end{array}$ & $\stackrel{\mathrm{C}}{\mathrm{C}}$ & $\begin{array}{l}\text { No } \\
\text { Weakness of foot dorsiflexors } 4^{+} \rightarrow 3 \\
\text { Weakness of neck flexors } 3 \rightarrow 2\end{array}$ & $\begin{array}{l}12-13 \\
12 \cdot 8-14\end{array}$ & $\begin{array}{l}12 \cdot 3-14 \cdot 5 \\
14-15\end{array}$ \\
\hline 12 & 10 & C & No & $11 \cdot 8$ & $12 \cdot 3$ \\
\hline 13 & 17 & C & $\begin{array}{l}\text { Incipient cataracts } \\
\text { Weakness of foot dorsiflexors } 2 \rightarrow 0\end{array}$ & $12 \cdot 3$ & $13 \cdot 0$ \\
\hline 14 & 18 & C & $\begin{array}{l}\text { Weakness of foot dorsiflexors } 2 \rightarrow 1 \\
\text { Weakness of plantar flexors } 5 \rightarrow 3\end{array}$ & $12 \cdot 5$ & $13 \cdot 5$ \\
\hline $\begin{array}{l}15 \\
16 \\
17 \\
18 \\
19\end{array}$ & 10 & $\begin{array}{l}C \\
C \\
C \\
C \\
D\end{array}$ & $\begin{array}{l}\text { ND } \\
\text { ND } \\
\text { ND } \\
\text { ND } \\
\text { Weakness of neck flexors } 5 \rightarrow 4 \\
\text { Weakness of distal forearm muscles } 4^{+} \rightarrow 4\end{array}$ & $\begin{array}{l}12 \cdot 0 \\
12 \cdot 8 \\
12 \cdot 0 \\
11 \cdot 0 \\
12 \cdot 5\end{array}$ & $\begin{array}{l}12.5 \\
13.5 \\
12.5 \\
12.5 \\
13.0\end{array}$ \\
\hline 20 & 6 & D & $\begin{array}{l}\text { Speech disturbance } \\
\text { Weakness of neck flexors } 5 \rightarrow 4\end{array}$ & $13 \cdot 5$ & $14 \cdot 5$ \\
\hline $\begin{array}{l}21 \\
22 \\
23\end{array}$ & $\begin{array}{l}8 \\
0 \\
0\end{array}$ & $\begin{array}{l}\text { D } \\
\text { D } \\
\text { D }\end{array}$ & $\begin{array}{l}\text { No } \\
\text { No } \\
\text { ND }\end{array}$ & $\begin{array}{l}12 \cdot 0 \\
15 \cdot 0 \\
13 \cdot 5\end{array}$ & $\begin{array}{l}12 \cdot 5 \\
16 \cdot 0 \\
14 \cdot 0\end{array}$ \\
\hline
\end{tabular}

For patients $1-4$ and 6 the numbers in brackets underneath the allele size in kb refer to the number of repeats determined by PCR for their minimally expanded alleles.

* Clinical severity in 1989: $A=$ asymptomatic, $B=$ minimal signs, $C=$ classically affected, $D=$ early onset and congenital $D M$.

* Clinical severity in 1989: $A=$ asymptomatic, $B=$ minimal signs, $C=$ classically affected, $D=$ early onset and congenital $D M$.
+ Clinical progression was considered when: $(A)$ new signs appeared, $(B)$ a decrease of at least one grade of strength was detected tClinical progression was considered when: (A) new signs appeared, (B) a decreas
using the MRC scale. Initial and final MRC grades are separated by an arrow.

$\ddagger$ The CTG repeat length is given as the size range of the smear of the EcoRI fragment containing the expanded repeat as ¥The CTG repeat length is given
determined by Southern blotting.

$\int$ Homozygous patients with one allele size listed above the other

$\mathrm{ND}=$ no neurological follow up available.

ECG, also including bilateral blocks.

Overt dilated cardiomyopathy shown by echocardiography.

Clinical progression:

Clinical weakness progression was assessed using the Medical Research Council (MRC) scale to measure muscle strength. A decrease of one or more grades in at least two distal muscle groups was considered as a parameter of progression. The appearance of any new clinical sign or weakness in a previously unaffected muscle was also considered.

DNA was isolated from peripheral blood samples and analysed by PCR to determine the number of CTG repeats in normal and small $(<200)$ repeat amplifications. PCR reactions were carried out in a total volume of $50 \mu \mathrm{l}$ with $700 \mathrm{ng}$ of genomic DNA. The conditions used were as described previously. ${ }^{14}$

PCR products were resolved by electrophoresis on $3.5 \%$ Nusieve gels or $3.5 \%$ Metaphor agarose gels or both. Repeats of $>200$ CTGs were analysed by Southern blotting. DNA $(5 \mu \mathrm{g})$ was digested with $E c o$ RI and electrophoresed on $0.6 \%$ agarose gels, denatured in $0.5 \mathrm{~mol} / 1 \mathrm{NaOH} / 1.5 \mathrm{~mol} / 1 \mathrm{NaCl}$, neutralised in $0.5 \mathrm{~mol} / 1$ Tris $(\mathrm{pH} 7.0) / 1.5 \mathrm{~mol} / 1$ $\mathrm{NaCl}$ and transferred onto a Hybond-N membrane in $10 \times$ SSC. Filters were probed with cDNA $25^{4}$ labelled with ${ }^{32} \mathrm{P}$ using the random priming method. ${ }^{15}$ The CTG repeat amplification was determined at the point of highest band intensity using densitometric scanning of the autoradiograph.

\section{Results}

Sixteen of the 23 patients in this study were neurologically evaluated and followed clinically over the five year period by one of us (JMM). Clinical progression of the disease during this period was assessed by comparing the initial and final clinical examination results. Of the five asymptomatic patients who were evaluated, one (patient 5 in the table) showed clinical manifestations of jaw myotonia and minimal weakness of the flexor muscles of the neck at his follow up examination. The remaining four subjects are still asymptomatic as judged by the lack of either EMG discharges or cataract. Clinical progression was seen in six of the symptomatic patients; patient 7 of class $B$, patients 11,13 , and 14 of class $C$, and patients 19 and 20 from class $D$.

Progressive muscle weakness was observed in all of these and, in addition, cataracts were detected in patients 7 and 13 (table).

Analysis of the CTG expansion sizes showed that none of six patients in class A showed any detectable increase of repeat number over the five year period between their samples. The 

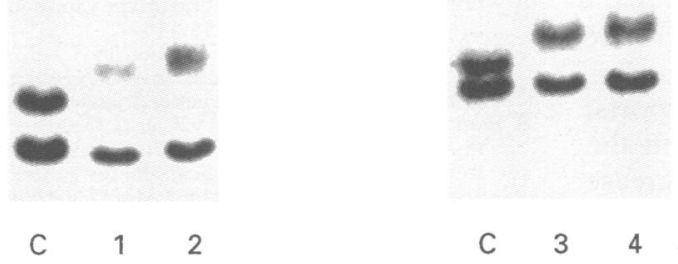

b
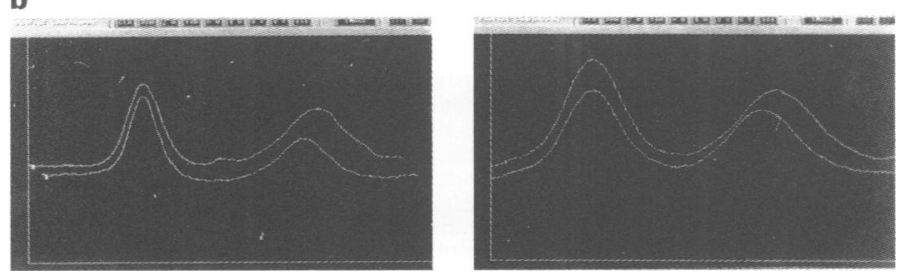

Figure 1 (a) CTG repeat expansion length in lymphocyte DNA after EcoRI digestion probed with cDNA25. Lane C, normal heterozygous control. Lanes 1 and 2 correspond to samples from patient 12 in 1989 and 1994 respectively. Lanes 3 and 4 correspond to samples from patient 15 with five years between sampling. (b) Profile comparison of expanded bands using a computer assisted imaging system (Bio-Profile). Left: lower curve corresponds to lane 1 and upper curve to lane 2. Right: lower curve corresponds to lane 3 and upper curve to lane 4.

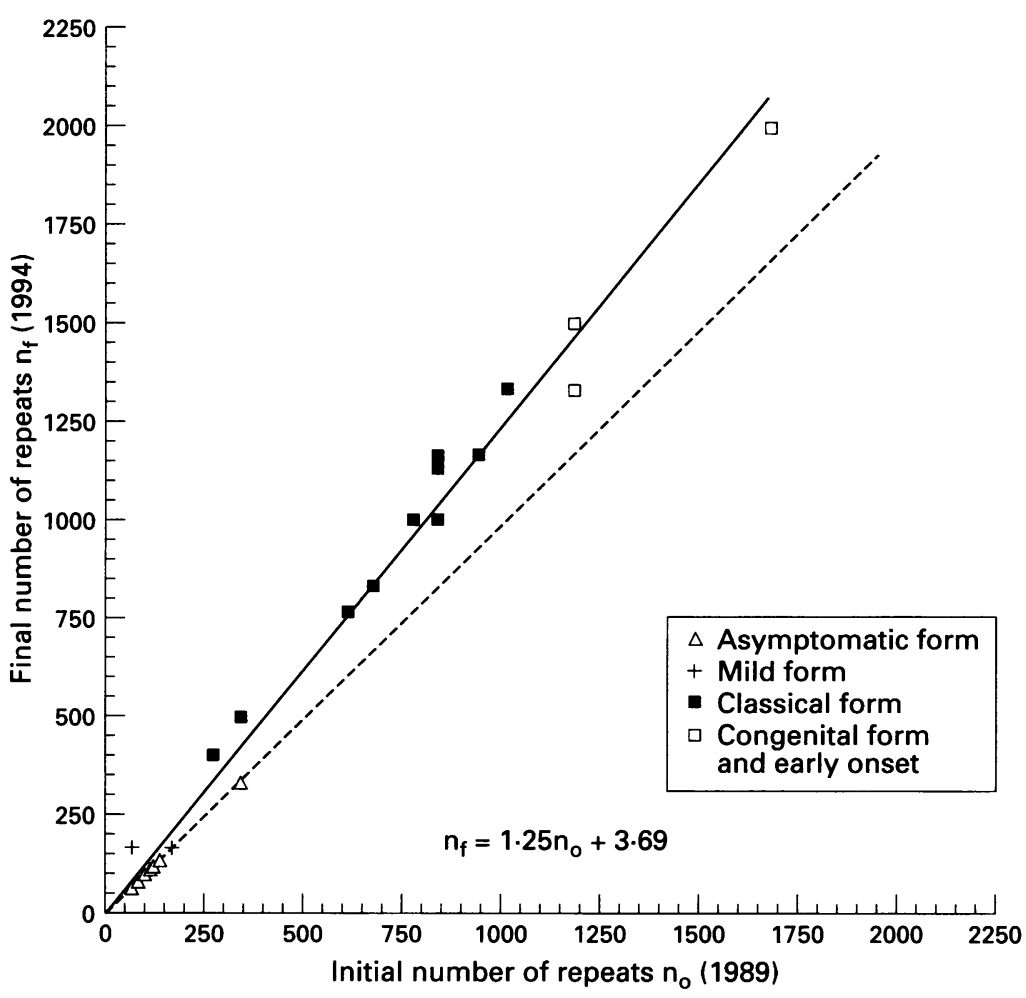

Figure 2 Plot of repeat numbers determined in $1994 v$ repeat number determined in 1989 for patients with differing clinical severities of DM. Continuous line represents line of best fit, dashed line represents position of no change in repeat number for the samples $\left(r^{2}=0.98, p \leq 0.00005, n=25\right)$.

expansions in this group of patients were determined by both Southern and PCR analysis where possible. Two out of three patients in class B showed progression of the repeat over the five years, whereas all of the patients in classes $C(12)$ and $D(5)$ showed some evidence of further expansion of the CTG repeat with time (table). Examples of the Southern data for patients 12 and 15 are shown in fig 1a along with the densitometric analysis of the autoradiographs in fig $1 \mathrm{~b}$.

Fig 2 represents the incremental increase of the CTG repeats for the two time points and clearly shows a correlation between the degree of expansion in this time period with the initial expansion length. This can be seen by an increasing deviation between the line of best fit and the line of no change with increasing repeat numbers $\left(r^{2}=0.98, p \leq 0.00005, n=25\right)$.

\section{Discussion}

We have investigated the CTG expansion length in $23 \mathrm{DM}$ patients of different classes of affectedness and shown that the expansion is not stable with time but continues to increase in a length dependent manner. This indicates that although there is substantial instability of the repeat during early embryogenesis as evidenced by the discordant monozygotic twin pairs, ${ }^{12}$ there is also continued expansion in lymphoblastoid tissues postnatally. It is interesting to note that no contractions of the repeat were seen in this analysis.

Our data suggest that even though there is progression of the symptoms in patient 5 who was asymptomatic five years ago but who now has jaw myotonia and weakness in the neck flexors, nevertheless there is no expansion of the repeat detectable by Southern blotting (PCR did not work on these samples). This is in contrast to those patients who were clinically manifesting symptoms five years ago and who already had a sizeable repeat expansion. With the exception of patient 8 they all show some degree of progression of the repeat expansion although only $50 \%$ of those where neurological follow up was performed show any clinical progression. The progression of the disease symptoms with no observable change in the expansion size in patient 5 suggests that the pathophysiological mechanisms by which the repeat expansion leads to disease symptoms does not require a "threshold" repeat size to be crossed before DM symptoms appear. Rather the data in the table suggest that age is a more important factor if the subject has an expansion of intermediate size.

These data are interesting when taken together with a similar follow up study comparing CTG expansion sizes in muscle biopsies. In these studies no progression of the repeat length was observed for the muscle expansions, even over a period of 15 years in one case ${ }^{16}$ However, the size of the expansions in the muscle biopsies was much larger than those in peripheral blood cells from the same patients. ${ }^{16}{ }^{17}$ It is possible that no increase in the muscle expansions was detected in those studies because the expansions were in most cases so large as to be at the limit of resolution of agarose gel systems. An alternative explanation is that there is a maximum limit to the degree of expansion which is tolerated within the cell and that expansions above that limit are selected against. It is therefore possible that the continued expansion would only be seen in relatively young 
DM patients. The expansion may reach its limit relatively early in adult life and hence studies with predominantly older patients would not have observed this effect.

The data presented here indicate that the repeat length does not correlate well with clinical symptoms, agreeing with previous reports, but that there is some predictive value in the absolute repeat length and its likely increase with time (fig 2).

Hence, patients with larger repeat numbers are more likely to see an increase in repeat number in their blood over a five year period with a $50 \%$ chance of clinical progression if they are already symptomatic at the initial examination.

This work was supported by the Spanish Ministry of Health (FIS 94/0350). NC gratefully acknowledges the support of the Muscular Dystrophy Group of Great Britain and Northern Ireland through grant number RA3/126/3. Research at CXWMS
is also supported by the Wellcome Trust and the Central Research Fund of the University of London.

1 Harper P. Myotonic dystrophy. 2nd ed. London: Saunders, 1989.

2 Aslanidis C, Jansen G, Amemiya C, et al. Cloning of the essential myotonic dystrophy region and mapping of the putative defect. Nature 1992:355:548-51.

3 Brook JD, McCurrach ME, Harley $\mathrm{H}$, et al. Molecular basis of myotonic dystrophy: expansion of a trinucleotide (CTG) repeat at the 3 -end of a transcript encoding protein kinase family member. Cell 1992;68:799-808.

4 Buxton J, Shelbourne P, Davies J, et al. Identification of probe that detects an unstable DNA segment specific to myotonic dystrophy patients. Nature 1992;355:547-8.

5 Fu YH, Pizzuti A, Fenwick RG Jr, et al. An unstable repea in a gene related to myotonic dystrophy. Science 1992; 255:1256-8.

6 Harley HG, Brook JD, Rundle SA, et al. Expansion of an unstable DNA region and phenotype variation in myotonic dystrophy. Nature 1992;355:545-7.

7 Mahadevan M, Tsilfidis C, Sabourin L, et al. Myotonic dystrophy mutation: an unstable CTG repeat in the $3^{\prime}$ untranslated region of the gene. Science 1992;255:1253-6.

8 Hunter AGW, Jacob P, O'Hoy K, et al. Decrease in the size of the myotonic dystrophy CTG repeat during transmission from parent to child: implications for genetic counselling and genetic anticipation. Am $\mathcal{F}$ Med Genet 1992;45:401-7.

9 Davies J, Yamagata H, Shelbourne P, et al. Comparison of the myotonic dystrophy associated CTG repeat in of the myotonic dystrophy associated CTG repeat in 29:766-9.

10 Harley HG, Rundle SA, MacMillan JC, et al. Size of the unstable CTG repeat sequence in relation to phenotype and parental transmission in myotonic dystrophy. $\mathrm{Am} \mathfrak{f}$ Hum Genet 1992;53:1164-74.

11 Lavedan C, Hofmann-Radvanyi H, Shelbourne $\mathrm{P}$, et al. Myotonic dystrophy: size- and sex-dependent dynamics of CTG meiotic instability, and somatic mosaicism. Am f Hum Genet 1993;52:875-83.

12 Lopez de Munain A, Marti Masso J, Cobo A, et al. CTG trinucleotide repeat variability in identical twins with myotonic dystrophy. Ann Neurol 1994;35:374-5.

13 Ashizawa T, Dubel JR, Harati Y. Somatic instability of CTG repeat in myotonic dystrophy. Neurology 1993;43:2674-8.

14 Cobo A, Martinez J, Martorell L, et al. Molecular diagnosis of homozygous myotonic dystrophy in two asymptomatic sisters. Hum Mol Genet 1993;2:711-16.

15 Feinberg AP, Vogelstein B. A technique for radiolabelling DNA restriction endonuclease fragments to high specific activity. Anal Biochem 1983;132:6-13.

16 Anvret M, Grandell U, Ahlberg G, et al. Larger expansions of the CTG repeat in muscle than in lymphocytes from of the CTG repeat in muscle than in lymphocytes from 2:1397-400.

17 Thornton C, Johnson K, Moxley R. Myotonic dystrophy patients have larger CTG expansions in skeletal muscle than in leukocytes. Ann Neurol 1994;35:104-7. 